\title{
Tensões Residuais em Soldagem a Arco: Uma Visão Holística
}

\author{
Andrii Mishchenko ${ }^{1}$, Américo Scotti ${ }^{1,2}$ \\ 1 Universidade Federal de Uberlândia - UFU, Grupo Centro para Pesquisa e Desenvolvimento de Processo de Soldagem - \\ Laprosolda, Uberlândia, MG, Brasil. \\ 2 University West, Production Technology West, Trollhättan, Sweden.
}

Recebido: 05 Jan., 2018

Aceito: 10 Mai., 2018

E-mails: asmwelder@gmail.com (AM), ascotti@ufu.br, americo.scotti@hv.se (AS)
Resumo: Encontram-se muitos exemplos na literatura onde se faz suposições relativas às tensões residuais que raramente são confirmadas na prática. Para validar esse enunciado, neste trabalho é apresentada uma visão crítica sobre o assunto através de uma revisão bibliográfica. Verificou-se uma série de resultados antagônicos quando pesquisadores tentaram, tanto experimentalmente, como por simulação, definir, quantificar, ou mesmo qualificar, o efeito separado de cada fator sobre a geração de tensões residuais. Concluiu-se que a razão para tal seria a falta de uma visão holística para estudar o assunto. Por isto, é proposto um diagrama que lista e classifica os fatores governantes na geração de tensões residuais como independentes e secundários, visando facilitar o entendimento do efeito de cada fator. Verificou-se também uma não harmonização, tanto na simbologia, como na terminologia, dos eixos e componentes das tensões residuais nas publicações. Dessa forma, se apresenta também uma proposta de simbologia e terminologia, com a intenção de facilitar a compreensão e transportabilidade de resultados. Espera-se, assim, ter este trabalho contribuído para um melhor entendimento das razões para que as suposições da literatura nem sempre sejam confirmadas na prática

Palavras-chave: Soldagem a arco; Tensões térmicas; Tensões residuais.

\section{Residual Stresses in Arc Welding: A Holistic Vision}

\begin{abstract}
There are several examples in current literature where assumptions regarding residual stresses are made, yet rarely confirmed in practice. To validate this statement, this work presents a critical view on the subject through a bibliographic review. A series of conflicting results were found when researchers attempted, both experimentally and by simulation, to define, quantify, or even qualify, the individual effect of each factor on residual stress generation. It was concluded that the reason for this would be the lack of a holistic view to study the subject. Therefore, a diagram is proposed, which lists and classifies as primary and secondary the governing factors related to the generation of residual stresses, to facilitate the understanding of the effect of each factor. It was also observed a lack of harmonization in publications, both in symbology and in terminology, of the residual stress axes and components. Therefore, a symbology and terminology proposal, with the intention of facilitating the comprehension and transportability of results, is presented. Eventually, from this work is therefore expected a better understanding of the reasons for the literature assumptions to be not always confirmed in practice.
\end{abstract}

Key-words: Arc welding; Thermal stresses; Residual stresses.

\section{Introdução}

A importância de se estudar Tensões Residuais (TR) em soldagem reside na capacidade de uma estrutura em suportar os esforços em serviço. Um exemplo de como as TR devem receber atenção dos responsáveis é dado por Lancaster (2005), onde o autor descreve um colapso de um vaso de pressão com amônia que aconteceu na África do Sul em 1973. De acordo com o autor, a maior contribuição para o colapso foi o campo de TR induzidas pelo processo de soldagem. O mesmo autor cita ainda outro colapso relacionado com TR causadas por soldagem, o da ponte Seongsu, que aconteceu em Seoul, 1994. Uma das causas do acidente foi corrosão induzida pelas TR causadas por uma solda.

Apesar da relevância do tema, estudar TR não é uma tarefa trivial. Existe, por exemplo, falta de contextualização na literatura corrente quando são usados os termos Tensões Térmicas (TT) e Tensões Residuais (TR), pois muitas vezes são tratados equivocadamente
Este e um artigo publicado em acesso aberto (Open Access) que permite uso, distribuição e reprodução em qualquer meio, sem restrições desde que sem fins comerciais e que 0 trabalho original seja corretamente citado. 
como sinônimos. Por exemplo, Pamnani et al. (2016) afirmam que as TR são geradas durante o processo de soldagem, o que contradiz a própria definição de TR dada pela AWS A3.0M/A3.0:2010 (AWS, 2010), como aquelas que estão presentes numa junta soldada e/ou material de base que estão livres de esforços externos e gradientes térmicos, ou seja, que permanecem depois da soldagem finalizar e a peça resfriar. Por outro lado, Eisazadeh e Aidun (2017) usam os termos tensões residuais e tensões transientes para definir tensões após soldagem e durante o processo de soldagem, respectivamente.

Scotti (2014) aponta a diferença entre TT e TR em soldagem por meio de um modelo descritivo. Tensões térmicas seriam aquelas geradas durante todo o ciclo térmico que passa cada região do material a ser soldado, tanto no aquecimento, quanto no resfriamento, a partir de e até a temperatura ambiente (um eventual pré-aquecimento ou pós-aquecimento fariam parte do ciclo térmico). Devido à existência de regiões não aquecidas do material durante soldagem, que agem como restrição à dilatação e contração da região aquecida, tensões trativas ou compressivas são geradas, tanto na região aquecida (geradora), como na não aquecida (restritoras). Estas tensões térmicas ao final do ciclo térmico (temperatura ambiente) representam as tensões finais distribuídas na região aquecida e não aquecida. Passam, assim, ao final, a ser chamadas de tensões residuais (TR).

A importância desta diferenciação é devida ao fato de que parte das tensões térmicas podem se manifestar antes de se transformar em tensões residuais, na forma de deformações (caso a peça não apresente resistência mecânica suficientemente alta para contrapor às TT). Ou mesmo na forma de colapso, quando as TT, sozinhas ou aliadas às outras tensões existentes, agem sobre fragilidades localizadas ou quando pontos de concentração de tensão superam o limite de ruptura do material, levando-o à fratura. Ou seja, a deformação e/ou colapso pode ocorrer mesmo na fase de resfriamento, mas tensões residuais, por definição, são aquelas TT acumuladas ao final do ciclo térmico. Seria, portanto, inadequado dizer que trincas de solidificação são devidas a TR, já que acontecem antes do final da geração total das TT. Além desta confusão conceitual de caráter terminológico, existem outras encontradas em estudos sobre tensões e deformações em soldagem, como quanto aos nomes dos vetores que definem o sentido das tensões (longitudinais ou transversais). Mais complicado se torna a análise quando não se define claramente em muitos trabalhos da literatura quais os parâmetros que são diretamente ou indiretamente responsáveis pelas gerações de tensões térmicas.

Tomando-se como base que uma revisão deve identificar de forma críticas espaços vazios do conhecimento para motivar pesquisadores a contribuírem com o fechamento das lacunas, este trabalho de revisão tem o objetivo de, tentando-se sempre homogeneizar definições e terminologias, apresentar uma visão holística das tensões de origem térmicas geradas e presentes num componente soldado, fundamentando-se em informações da literatura e modelos/proposições dos autores.

\section{Representação Vetorial das Tensões e Terminologia Propostas}

Cabe agora discutir a simbologia das tensões residuais quanto às direções de como se distribuem. A maneira mais comum de se fixar os eixos de referência é ilustrada pela Figura 1 e adotada, por exemplo, por Teng e Lin (1998), onde tem-se o eixo $\mathrm{Y}$ como longitudinal ao cordão de solda, o $\mathrm{X}$ como transversal e o $\mathrm{Z}$ como normal, escolhendo como referência o centro da chapa de teste. Entretanto, há muita divergência de simbologia entre autores que mediram TR em seus trabalhos. Por exemplo, no trabalho de Pouget e Reynolds (2008), os autores definem as TR como longitudinais e transversais sem especificar os eixos de referência. Park et al. (2004) e Heinze et al. (2012a) usaram o sistema de referência parecido com o de Teng e Lin (1998), porém definem o eixo $Z$ como eixo longitudinal ao cordão de solda, $X$ como transversal e $Y$ como normal. Schroepfer et al. (2017) usou apenas o eixo $Y$, mas para indicar a tensão transversal ao cordão de solda. Ter conhecimento preciso do eixo de atuação da TR é de extrema importância. Por exemplo, Nitschke-Pagel e Wohlfahrt (2002) menciona que em soldas de uma camada sem gradientes de temperatura na direção da espessura, provavelmente as tensões residuais longitudinais serão a componente mais significante e as tensões residuais transversais alcançarão aproximadamente $1 / 3$ dos valores das longitudinais.

Não que exista a maneira certa ou errada, mas neste trabalho segue-se a representação da Figura 1. Além disso, os autores do presente trabalho acham importante definir não só a direção das componentes das tensões, mas também em que eixo $(X, Y, Z)$ as tensões estão atuando. Em muitos trabalhos, entre eles o do Heinze et al. (2012a), fica difícil de distinguir em quais eixos se referem as TR longitudinais e transversais calculadas 


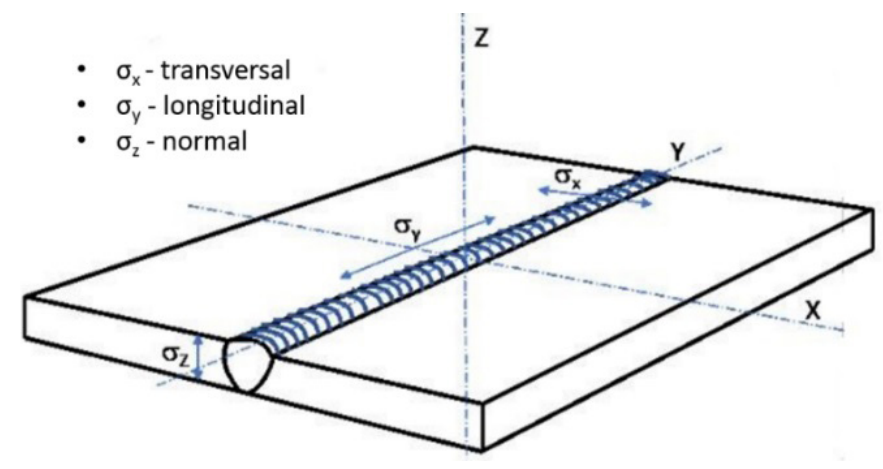

Figura 1. Representação esquemática dos componentes de tensão numa chapa tridimensional. Fonte: Elaborada pelos autores.

e medidas. Por isto nesse trabalho se propõe uma definição para as TR atuantes. Pela proposta, as componentes são representadas pela letra grega $\sigma$ e índices subscritos X e Y no plano de uma chapa de acordo com o sistema de coordenadas apresentado na Figura 2, em que as curvas mostram como variam as TR longitudinais e transversais ao longo dos eixos $X$ e Y. $\sigma_{y-x}$ seria, então, a tensão longitudinal $\left(\sigma_{y}\right)$ ao longo do eixo $X$, à uma distância do eixo de referência $Y . \sigma_{X-x^{\prime}}$ por sua vez, seria a tensão transversal ao longo do eixo $X$, à uma dada distância do eixo de referência $X . \sigma_{y-y}$ representaria a variação de tensão longitudinal ao longo do eixo $Y$, à uma dada distância do eixo de referência $X$. Finalmente, $\sigma_{x-y}$ seria a variação de tensão transversal ao longo do eixo $Y$, a uma dada distância do eixo de referência Y. Acredita-se que, assim, fica mais fácil comparar resultados.

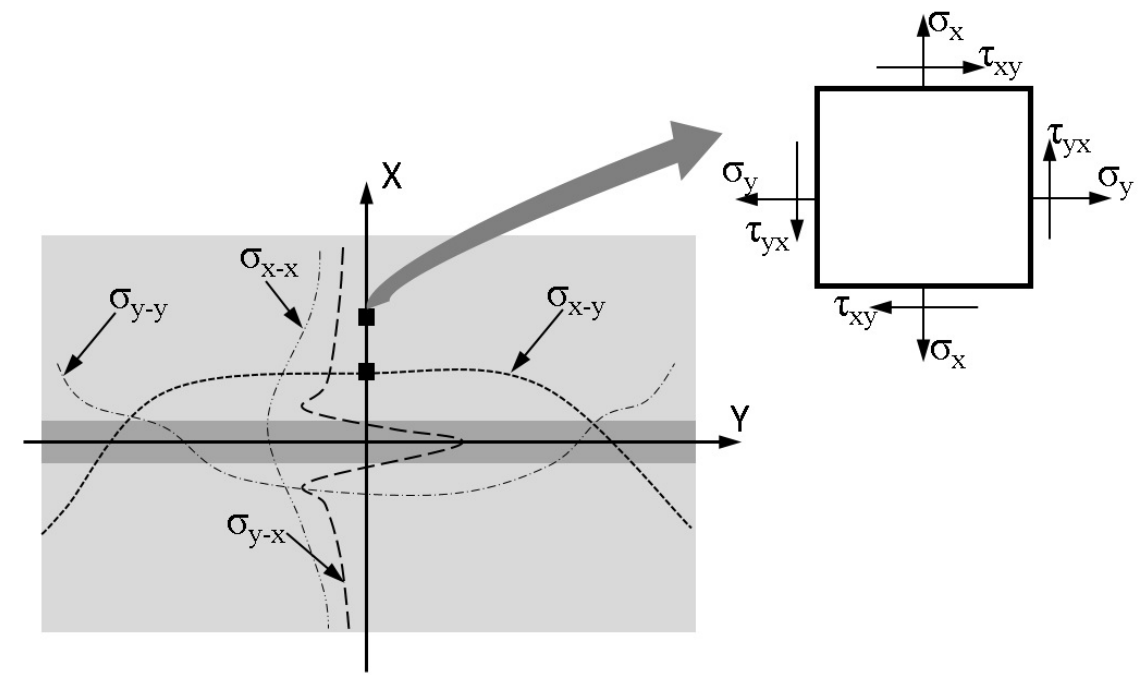

Figura 2. Esquematização de distribuição das TR em um plano sobre uma chapa soldada e representação proposta pelos autores para cada componente das tensões. Fonte: Elaborada pelos autores.

\section{Influência dos Parâmetros Operacionais Sobre a Geração de TR}

O Michaelis (2016) define a palavra "parâmetro" como "elemento variável que participa da elaboração de um conjunto e que também constitui um todo". Por sua vez, a palavra "operacional" é definida como algo relativo à operação. Portanto, a frase "parâmetros operacionais de soldagem" significa um conjunto de elementos variáveis relativos à operação de soldagem, mas que constituem um todo. 


\subsection{A energia de soldagem e sua relação com a geração de TT}

Palani e Murugan (2006) e Kim e Eagar (1993) comentam que corrente, tensão e velocidade de soldagem são os principais parâmetros operacionais do processo. O conjunto desses três parâmetros define, de forma genérica, a energia de soldagem. É importante citar que calor imposto ("heat input") tem sido erroneamente referenciado em muitos artigos como sinônimo de energia de soldagem. Na verdade, calor imposto é uma parte da energia de soldagem que efetivamente é entregue à peça. Entretanto, a mensuração do calor imposto é um processo complexo, pois depende de um fator experimental (eficiência térmica) de difícil determinação. A eficiência térmica depende não só do processo, mas dos parâmetros de soldagem e da geometria e estado energético da peça. Além disto, depende do método de medição, que normalmente são imprecisos. Energia de soldagem por sua vez, é razoavelmente fácil de calcular, como a média das potencias instantâneas dividida pela velocidade de soldagem. Por isto, nesse trabalho, será apenas utilizado o termo energia de soldagem, que tem sido extensivamente citada como parâmetro que governa a geração de TT. Por exemplo, Lin e Lee (1997) e Xu et al. (2014) estudaram o efeito da energia de soldagem sobre TR em peças de aço inoxidável austenítico. Lin e Lee avaliaram TR em chapas de aço AISI 304 utilizando métodos experimentais, enquanto Xu et al. (2014) fizeram uma simulação de soldagem de tubos de mesmo material (o efeito de energia de soldagem sobre as TR para 3 níveis de energia, $3,0 \mathrm{~kJ} / \mathrm{cm}$, $3,5 \mathrm{~kJ} / \mathrm{cm}$ e 4,0 kJ/cm, respectivamente). Apesar de ter estudado TR em materiais parecidos, Lin e Lee (1997) e Xu et al. obtiveram resultados diferentes. Lin e Lee (1997) não recomendam utilização da energia de soldagem elevada. Em contraste, Xu et al. (2014) observaram pouca influência da energia de soldagem sobre a distribuição e pico das TR na peça analisada.

Estudando a influência de energia de soldagem sobre a deformação e tensões residuais na soldagem de chapas de aço carbono ASTM A131, Colegrove et al. (2009) afirmam que com aumento da energia de soldagem a largura do pico de TR longitudinal aumenta também, enquanto o valor máximo de TR permanece relativamente constante. Foi observado o aumento do grau de distorção da peça para energias de soldagem mais altas. Dados similares foram obtidos por Schroepfer e Kannengiesser (2014), em cujo artigo os autores apresentaram o efeito de energia de soldagem sobre as TR na união de chapas de $8 \mathrm{~mm}$ de espessura de aço de alta resistência. Similarmente à Colegrove et al. (2009), Schroepfer e Kannengiesser observaram aumento da largura do pico das TR, tanto da longitudinal, como da transversal, com o aumento da energia de soldagem, sendo que o valor máximo das TR não foi alterado (independentemente do material da chapa de teste).

O fato de uma maior energia de soldagem não afetar o valor máximo absoluto da TR, porém aumentando-se a área de distribuição desse valor, foi previsto por Scotti (2014) em seu modelo descritivo de 5 barras, onde o autor afirma que a intensidade das forças (tensões) seria a mesma independentemente da energia, pois a intensidade das tensões depende essencialmente do limite de escoamento do material naquela temperatura. Mas a largura da faixa em que as tensões são geradas é maior, ou seja, um maior volume do material ficará sob ação de tensões térmicas.

Já as tendências observadas por Unnikrishnan et al. (2014) são diferentes das dos autores acima. Unnikrishnan et al. (2014) estudaram o efeito de energia de soldagem sobre TR em cordões de solda feitos por deposição em chapas de aço AISI 304. Os autores observam que uma energia de soldagem maior resulta em TR de tração na região perto do cordão de solda, enquanto uma energia de soldagem menor produz TR de compressão na mesma região. Os autores destacam que nas regiões afastadas do cordão de solda, as TR produzidas por soldagem com menor energia são compressivas de valor próximo ao limite de escoamento do material, enquanto as TR produzidas pela soldagem com maior energia são próximas de zero. Os autores não destacam, entretanto, que uma mesma distância do cordão de solda para soldagens com diferentes energias significa materiais com diferentes propriedades sob a ação das tensões a uma determinada distância do cordão de solda.

Analisando os resultados nem sempre concordantes de diferentes autores, pode-se concluir pela dificuldade de se analisar o efeito da energia de soldagem (ou mesmo calor imposto) sobre a geração de TR, uma vez que energia de soldagem é um parâmetro de controle (também denominado de parâmetro secundário). Parâmetros de controle ou secundários são aqueles que afetam os parâmetros independentes (também denominados parâmetros primários), os quais que realmente governam a geração de TT. Exemplos de parâmetros independentes para geração de TT seriam a taxa de resfriamento (controlando as características metalúrgicas/propriedades mecânicas) e o volume aquecido a uma dada temperatura (controlando a contração do material durante o resfriamento). 
Esta afirmação está de acordo com o Nitschke-Pagel e Wohlfahrt (2002), que disseram que TR em soldagem é uma consequência da contenção da contração do metal onde transformação de fase ocorre combinada com a restrição do volume aquecido. A Figura 3 apresenta a inter-relação entre os dois parâmetros independentes e os parâmetros secundários que os modificam.

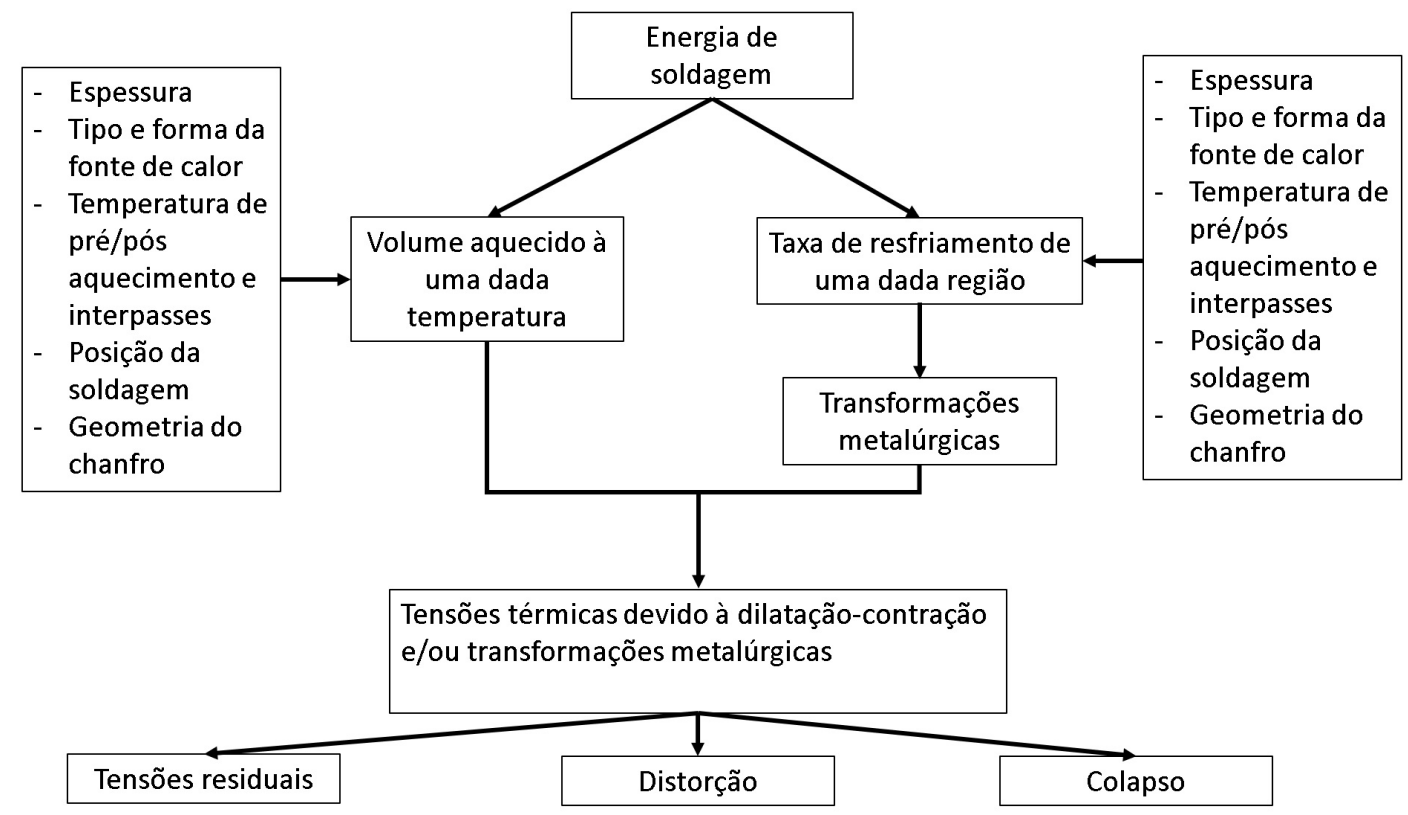

Figura 3. Diagrama esquemático elaborado pelos autores representando como a energia de soldagem age sobre os fatores que realmente governam a geração de tensões térmicas e, consequentemente, tensões residuais, distorções e/ou colapso.

Neste contexto, Ye et al. (2015) avaliaram a influência do tipo de chanfro (V, X e K) sobre as TR na soldagem multipasse, mantendo-se a quantidade de passes para cada tipo de junta (chapas de $10 \mathrm{~mm}$ de espessura de aço AISI 304). Ou seja, procuraram estudar o efeito de um parâmetro secundário ao manter um parâmetro independente, no caso o volume aquecido, constante (o efeito de transformações de fase no estado solido foi eliminado ao se escolher aço austenitico como metal de base). Para conseguir preencher os chanfros diferentes com mesma quantidade de passes, os autores adotaram a preparação em $V$ com abertura de $60^{\circ}$ como referência. Os chanfros em $\mathrm{K}$ e X foram confeccionados de tal maneira a dar o mesmo volume do chanfro em $\mathrm{V}$ de $60^{\circ}$. Como resultado, os autores observaram que o chanfro em $\mathrm{V}$ produz TR longitudinais e transversais de maior valor e distribuídas em uma maior área, comparado com os chanfros em $\mathrm{K}$ e X.

De maneira indireta, os resultados dos trabalhos de Colegrove et al. (2009) e Schroepfer e Kannengiesser (2014) (aumento da largura do pico tanto da TR longitudinal, como da transversal com aumento da energia de soldagem) indicam que as energias de soldagem mais altas aquecem um volume maior de material e no final as tensões residuais são distribuídas por um volume maior sem alterar significativamente o seu valor máximo.

\subsubsection{O efeito de volume aquecido sobre a geração de TT}

Pode-se imaginar que quanto maior o volume de metal aquecido maior será a contração do material durante o resfriamento, quando então se gera as TT. O volume total aquecido geralmente é governado pelos parâmetros geométricos da junta soldada e é composto pela somatória do volume de metal depositado no chanfro e fundido do MB (ZF) e pelo volume de metal de base aquecido pela fonte de calor (ZAC e sub-ZAC). O volume de metal depositado, por sua vez, depende da geometria e dimensões do chanfro, enquanto o volume de metal fundido e aquecido pela fonte de calor depende do processo de soldagem utilizado e da espessura da chapa. Segundo Masubuchi (1980), as maiores alterações volumétricas durante um ciclo térmico da solda são observadas no metal 
de base. Segundo o autor, da contração/expansão transversal total de uma junta soldada apenas $10 \%$ se deve ao resfriamento/aquecimento do metal fundido, sendo o restante devido ao metal de base. Naka (1950) já afirmava que a maior contração no sentido transversal numa soldagem ocorre no metal de base e não no cordão de solda.

Apesar do volume ser uma variável primária na geração de TT, hierarquicamente sob a ação da energia de soldagem, como visto na Figura 3, o volume em si é governado por vários outros fatores, como a espessura da chapa, a geometria e forma do chanfro, posição de soldagem, tipo da fonte de calor, etc. Por exemplo, na união de chapas mais espessas, um volume maior será aquecido (maior energia de soldagem demandada). Entretanto, a chapa muito grossa pode ser soldada em vários passes com volumes por passe muito menor do que o volume total da junta. Desta forma, é muito difícil a análise do efeito do volume sobre a geração de TR. Por este motivo, ou por não perceberem esta relação de causa e efeito entre fatores independentes e secundários, em muitos trabalhos se tenta estudar o efeito de fatores secundários sobre a geração de TT, que potencialmente torna a análise ainda mais complicada.

Neste contexto, Teng et al. (2002) avaliaram numericamente o efeito dos parâmetros geométricos de uma junta soldada, tais como espessura da chapa e ângulo de abertura, entre outros, sobre as TR geradas e as consequências sobre a resistência à fadiga. O material das chapas de teste utilizadas foi aço ASTM A36 e as chapas foram soldadas em junta de topo com preparação em V. Foi observado que quando a espessura da chapa ou o ângulo de abertura do chanfro aumentam, as tensões residuais (TR) longitudinais aumentam também. Entretanto, as simulações feitas por Teng et al. (2002) não receberam validação experimental.

Porém, a análise dos parâmetros governantes na geração de TR deve ser feita com cuidado. Por exemplo, além de volume, a temperatura em que o mesmo foi aquecido também é importante. Chapas de um mesmo material, mas de espessuras diferentes, são exemplos típicos deste enunciado. Chang e Teng (2004) avaliaram numericamente e experimentalmente as TR em chapas de aço A36 de 4,5 mm de espessura. A junta foi feita em três passes com uma energia de soldagem média de $3 \mathrm{~kJ} / \mathrm{mm}$ por passe. $O$ valor máximo de TR longitudinal medido por autores foi de aproximadamente $400 \mathrm{MPa}$. Por outro lado, Teng et al. (2002) simularam numericamente a soldagem de chapas do mesmo material, porém com a espessura de $32 \mathrm{~mm}$. A junta foi preenchida por 6 passes com energia de soldagem média de $1,3 \mathrm{~kJ} / \mathrm{mm}$ por passe. O valor máximo de TR longitudinais obtido por Teng et al. (2002) foi de aproximadamente $220 \mathrm{MPa}$. Comparando os dois trabalhos, poder-se-ia dizer que a chapa mais fina apresenta maior TR após soldagem. Porém, numa visão holística, a energia de soldagem por passe da chapa mais fina foi quase duas vezes maior. Além disto, a chapa fina foi soldada com três passes, enquanto a mais grossa com seis

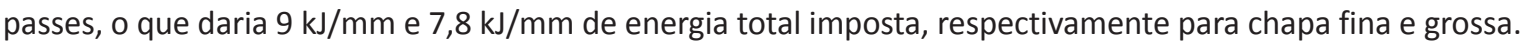

Maiores tensões residuais para chapas mais finas foram também observadas por Lee et al. (2012). Em seu trabalho, Lee et al. (2012) avaliaram experimentalmente a distribuição das tensões residuais na soldagem de chapas de aço microligado de alta resistência em juntas de T. Quando os autores compararam as tensões residuais em juntas feitas com chapas de $8 \mathrm{~mm}$ e $12 \mathrm{~mm}$ de espessura, as tensões residuais transversais foram maiores para chapa mais fina. Entretanto, como afirmam Lee et al. (2012), este fato foi uma particularidade e que a tendência geral é aumento da tensão residual com aumento da espessura da chapa. Lee et al. (2012) explicaram o aumento das tensões residuais para chapa mais fina por meio de relação entre velocidade de resfriamento para uma dada espessura e gradientes térmicos. Para chapas mais finas, o aquecimento ao longo da espessura é aproximadamente uniforme, o que faz com que a chapa perca calor por condução e convecção. Neste caso, os gradientes térmicos são mínimos, porém a taxa de resfriamento é alta. Por outro lado, ainda segundo esses autores, com aumento da espessura da chapa a velocidade de resfriamento diminui e os gradientes térmicos aumentam. Segundo Lee et al. (2012), para um dado material existe uma espessura quando o efeito de velocidade de resfriamento mais lenta prevalece sobre o efeito de gradientes térmicos e a tensão residual resultante é menor comparando com a chapa mais fina. Porém, com aumento da espessura da chapa, esses autores citam, sem justificar, que os gradientes térmicos crescem e a velocidade de resfriamento permanece praticamente constante. Isso faz com que as tensões comecem a crescer novamente com aumento da espessura.

Outro exemplo relacionado ao efeito dos gradientes térmicos foi observado por Ishizaki et al. (2008), que utilizaram resfriamento por jato de $\mathrm{CO}_{2}$ para diminuir TR longitudinais e transversais em soldagem de um aço inoxidável austenitico. Quando aplicado o resfriamento por $\mathrm{CO}_{2}$, os autores encontraram menores TR para maiores gradientes térmicos. Um fator que não foi discutido por Ishizaki et al. (2008) é a redução de volume do metal aquecido pelo resfriamento forçado, que, por hipótese, poderia ter sido a causa para redução das TR. Deste modo, 
pode-se observar que as TR em chapas finas ficaram maiores do que em chapa grossa, o que contradiz os resultados de Vakili-Tahami e Sorkhabi (2009) (quanto maior a espessura da chapa, maior a tensão residual).

Como apontam Nitschke-Pagel e Wohlfahrt (2002), a distribuição das TR é governada por expansão e contração restringida, pois nos aços estudados não havia transformações metalúrgicas no estado solido. Pode-se supor que as TR em tais aços são governadas por quantidade de volume do metal aquecido e posteriormente resfriado. Essa hipótese foi comprovada indiretamente por Sudheesh e Prasad (2011). Eles estudaram o efeito de resfriamento (trailing sink) sobre tensões residuais na soldagem TIG de chapas finas de aço carbono comum e observaram uma redução significativa das TR longitudinais numa zona de $10 \mathrm{~mm}$ a $75 \mathrm{~mm}$ a partir do centro do cordão, quando o resfriamento foi aplicado. Entretanto, segundo os resultados dos autores, a aplicação de resfriamento por nitrogênio líquido não fez efeito perceptivo sobre as tensões residuais na ZF ou ZAC. As TR no trabalho do Sudheesh e Prasad foram reduzidas no metal de base e segundo as imagens de campos de temperatura é exatamente no metal de base onde a temperatura foi reduzida com maior eficácia.

Avaliando numericamente a influência do resfriamento forçado sobre TR na soldagem multipasse de tubo de aço AISI 316, Jiang e Yahiaoui (2008) observaram redução de TR axiais de natureza trativa quando o resfriamento mais intensivo foi aplicado. Diferentemente do trabalho de Sudheesh e Prasad (2011), Jiang e Yahiaoui (2008) avaliaram o efeito do resfriamento de ambos os lados da junta. Os autores simularam 8 passes de solda, sendo o primeiro feito com processo TIG e uma energia de soldagem de $0,48 \mathrm{~kJ} / \mathrm{mm}$ e o restante com uma energia de soldagem de aproximadamente $1,10 \mathrm{~kJ} / \mathrm{mm}$. Segundo os autores, o resfriamento mais intenso causa tração na superfície e contração no interior da chapa de teste. No final do processo de soldagem, a tensão trativa se transforma em compressiva e vice-versa. Por meio de resfriamento forçado da junta, Jiang e Yahiaoui (2008) conseguiram controlar o volume de metal contraído e alterar o perfil de distribuição e magnitude de TR. Resultados um pouco diferentes foram obtidos por Jiang et al. (2012), onde os autores avaliaram numericamente o efeito de resfriamento forçado sobre TR na soldagem de chapas de aço AISI 316. Dos resultados obtidos, pode-se concluir que o resfriamento forçado tem pouca influência sobre TR. Por exemplo, os autores observaram a redução $70 \mathrm{MPa}$ no pico das TR longitudinais na ZAC, comparado com a soldagem sem resfriamento (de $360 \mathrm{MPa}$ para $290 \mathrm{MPa}$ ). Além disso, tanto as TR longitudinais como transversais ficaram maiores nas zonas afastadas do cordão de solda quando o resfriamento forçado foi aplicado.

\subsubsection{O efeito das transformações metalúrgicas sobre TT}

A taxa de resfriamento (controlando as características metalúrgicas/propriedades mecânicas) é o segundo parâmetro independente na geração de TT, segundo Figura 3. Enquanto alguns autores, como, por exemplo, Jiang e Yahiaoui (2008), Li et al. (2012) e Sudheesh e Prasad (2011) declaram que uma taxa de resfriamento elevada é benéfica à redução de TR, outros, como, Choi e Mazumder (2002) afirmam o contrário (aumento das TR de tração no sentido transversal na ZF e ZAC com aumento da velocidade de soldagem). A situação torna-se mais complicada quando se estuda TR em aços que sofrem transformações metalúrgicas no estado sólido. Por isto, vários trabalhos procuram estudar o efeito das transformações de fase através de simulações (físicas e computacionais).

Jones e Alberry (1978) simularam fisicamente as TR em barras de aços C-Mn, baixa liga e inoxidável, e observaram o perfil de evolução das TT durante um resfriamento similar para todos os aços avaliados, como ilustrado na Figura 4. $\mathrm{O}$ aumento de tensões de tração com a redução da temperatura a partir de $1320{ }^{\circ} \mathrm{C}$ é relacionado com contração restringida e depende do material (por exemplo, maior razão de crescimento da TT para o aço $12 \mathrm{CrMo}$ e menor para o C-Mn). Porém, durante o resfriamento acontece também transformação de fases, que têm caráter expansivo (introduzindo tensões de compressão sobre as tensões trativas). No caso da Figura 4, estas transformações ocorreram com tamanho volume de contração que as TT chegaram até a deixar o material sob um estado de tensão trativa ao final das transformações. Após as transformações, o material continua se contraindo e as TT tornam-se progressivamente trativas (novamente com razões de crescimento da TT conforme a composição do aço, ou melhor, da microestrutura formada). Ao final, em função das transformações, se tem diferentes TR para cada aço (no caso maior para o aço $2 \mathrm{CrMo} \mathrm{e} \mathrm{menor} \mathrm{para} \mathrm{o} \mathrm{aço} 12 \mathrm{CrMo}$ ). Fica evidenciado, portanto, o papel importante da transformação de fase na geração de TT.

Deng e Murakawa (2006) simularam numericamente o efeito de transformações metalúrgicas sobre TR na soldagem de tubos de aço de alta resistência. Os autores avaliaram o efeito de alteração das propriedades mecânicas e alteração volumétrica devido à transformação martensitica do cordão sobre a magnitude e distribuição 


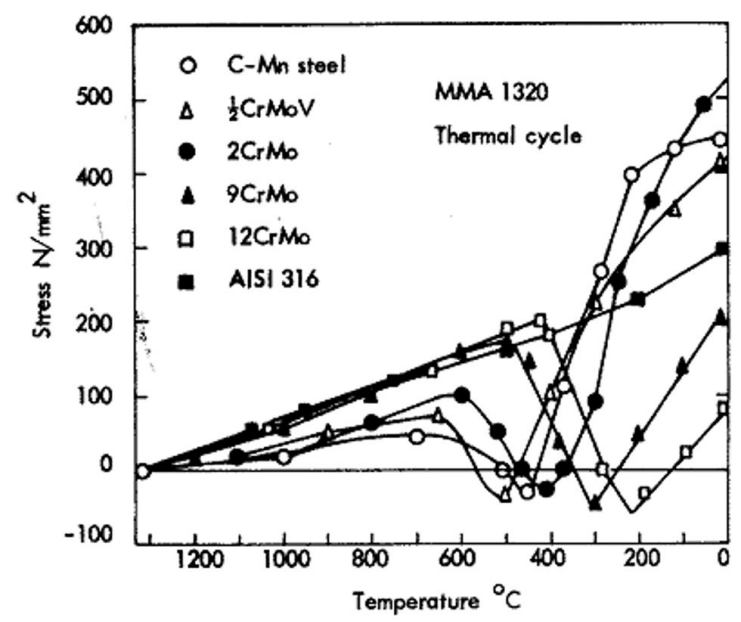

Figura 4. Perfil das tensões térmicas (TT) geradas durante o resfriamento em simulação física e tensões residuais (TR) resultantes para vários aços soldados sob mesmo processo e ciclo térmico de soldagem (Jones e Alberry, 1978).

das tensões residuais para uma energia de soldagem constante. Foi observado que alteração de volume devido à transformação metalúrgica pode mudar o sinal das tensões residuais axiais, enquanto a alteração das propriedades mecânicas muda apenas a magnitude das tensões residuais. O mesmo caso, porém utilizando material diferente, foi validado experimentalmente por Lee (2008), onde o autor simulou soldagem multipasse de um aço de alta resistência. Apesar de energia de soldagem ter sido diferente para cada passe, o autor observou que quando o efeito da transformação martensitica é incluso no modelo proposto as tensões longitudinais no centro do cordão de solda depois de resfriamento total diminuem de $800 \mathrm{MPa}$ para $600 \mathrm{MPa}$.

Lee e Chang (2011) também simularam numericamente o efeito de transformação austenita-martensita sobre as tensões residuais na soldagem de tubos de aço de alta resistência. Para um valor fixo de energia de soldagem, foi observado um decréscimo nas tensões residuais axiais quando a transformação austenita-martensita foi inclusa no modelo. Os autores atribuem esse efeito às mudanças volumétricas provocada pelas transformações que ocorrem no cordão de solda. Resultados diferentes são obtidos quando o efeito de transformação martensitica é estudado em aços de baixo teor de carbono. Como foi comprovado por Deng (2009), na soldagem de aços de baixo carbono a transformação martensitica não tem grande influência sobre as TR longitudinais, independente da energia de soldagem. $O$ autor simulou TR em dois tipos de aços, sendo um com baixo teor de carbono e outro com médio. Chegou à conclusão de que apenas no aço com médio teor de carbono a transformação martensitica diminui TR na ZAC e ZF.

Quando se solda um material que passa por transformações metalúrgicas no estado solido, torna-se difícil de separar a influência do volume de metal aquecido da influência de transformações metalúrgicas sobre geração de TR, principalmente quando não se pode manter exatamente o mesmo volume aquecido. Taljat et al. (1998) justificam a grande influência da transformação austenita-martensita por meio de dois fatores, a saber, mudança volumétrica e alteração das propriedades mecânicas do metal. Entre esses dois fatores, Taljat et al. (1998) destacam as mudanças volumétricas, enquanto a alteração de propriedades mecânicas não teriam tanta influência.

Uma maneira proposta para estudar a influência separadas dessas transformações sobre TR é por meio de diagramas típicos, como apresentado na Figura 5. Nitschke-Pagel e Wohlfahrt (2002) apresenta a evolução de tensão axial durante resfriamento em barras de aços ferritico-perlitico, bainitico e martensitico. Segundo esses autores, quando o aço sofre transformações metalúrgicas no estado solido, a expansão térmica é sobreposta pela expansão volumétrica devido às transformações. Esta sobreposição resulta em alteração completa do perfil de TR. Por exemplo, na Figura 5 está apresentado um comportamento simulado fisicamente de aços que sofrem transformação ferrita-perlitica, martensitica ou bainitica. Para uma mesma composição química do aço, o produto da transformação de fase vai depender da velocidade de resfriamento. No caso, a transformação martensítica foi a que proporcionou menor TR, no caso, compressiva. 


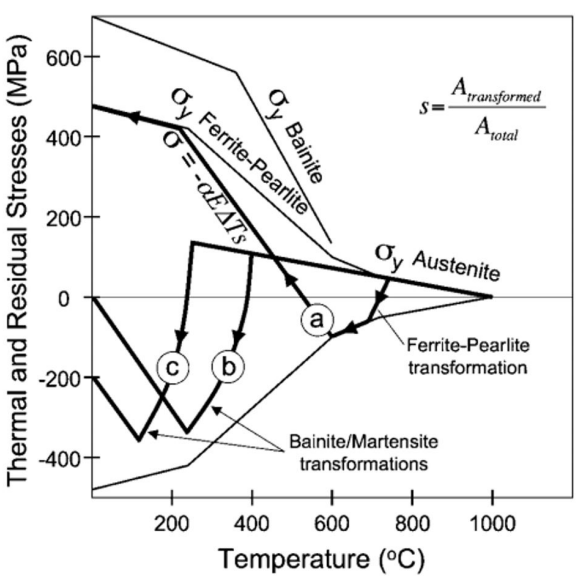

Figura 5. Representação esquemática de evolução de tensão térmica axial em aços com estrutura ferrita perlita (a), bainita (b) e martensita (c), desenvolvida por Nitschke-Pagel e Wohlfahrt (2002), onde: $\sigma_{y}$ é a curva de limite de escoamento em função da queda de temperatura para diferentes microconstituintes.

Este fenômeno foi observado por vários autores que estudaram o efeito de transformações metalúrgicas sobre TR. Por exemplo, Deng e Murakawa (2006) observaram que quando o efeito de transformação martensitica foi incluso no modelo numérico de soldagem de topo de um aço ao carbono martensitico, as tensões residuais axiais na ZF invertem o seu sinal quando comparado com o modelo onde somente a alteração do limite de escoamento foi considerado. Xu et al. (2015) observaram que no aço microligado de alta resistência, as TR de tração podem passar a ser de compressão devido a transformação bainitica na ZAC durante o resfriamento após soldagem. Entretanto, Xu et al. alertam para que se a temperatura de transformação martensitica não for baixa suficiente, a compressão induzida por transformação não será suficiente para aniquilar a tensão de tração devido a contração térmica e ao final do resfriamento as TR permanecem trativas.

A Figura 6 é outra demonstração do efeito das transformações sobre as TR finais, após soldagens pelo processo A-TIG. As TR foram medidas pela técnica de furo cego. Como observado na figura, as TR crescem até um certo ponto com a profundidade da medição. Kumar et al. (2017) justificam esse crescimento pela alteração superficial de caráter compressivo. Observa-se também que as TR são maiores para maiores energias de soldagem (menor taxa de resfriamento). Kumar et al. (2017) justificam essas tendências por meio da transformação martensitica, que seria maior para a taxa de resfriamento mais elevada. Entretanto, os autores não comentam o efeito concorrente do volume aquecido que também seria menor para menor energia de soldagem. É interessante apontar a diferença nas tendências observadas em materiais que sofrem transformações em estado sólido por Kumar et al. (2017) e Jones e Alberry (1978). Kumar et al. (2017) observaram menores TR para menor energia de soldagem e maior taxa de resfriamento enquanto que Jones e Alberry (1978) recomendam reduzir taxa de resfriamento (maior energia de soldagem) para obter menores TR.
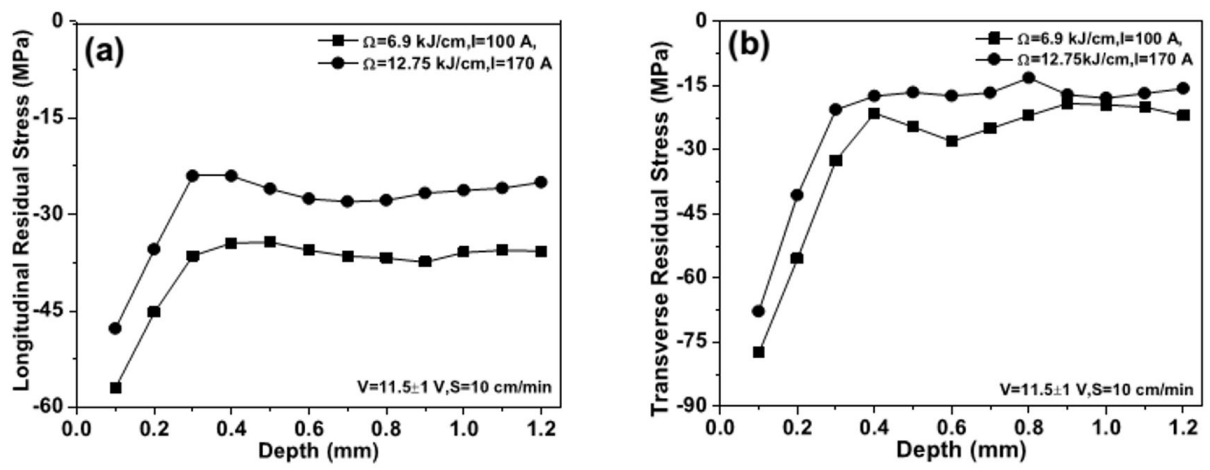

Figura 6. TR longitudinais (a) e transversais (b) na ZF para duas energias de soldagem diferentes (Kumar et al., 2017) em função da profundidade na ZF. 
Entretanto, ainda há algumas controvérsias nos trabalhos científicos em relação ao efeito da mudança de propriedades mecânicas na região transformada, como, por exemplo, nos trabalhos de Bezerra et al. (2006), Deng e Murakawa (2006) e Taljat et al. (1998). Os resultados obtidos por Deng e Murakawa (2006) apontam que a inclusão do efeito de transformação martensitica em simulação numérica altera o sinal de TR longitudinal de positivo para o negativo, enquanto Bezerra et al. (2006) e Taljat et al. (1998) observaram apenas alteração de magnitude de TR quando se inclui o efeito de transformação de fase em modelos numéricos de soldagem.

Deng e Murakawa (2006) simularam e avaliaram experimentalmente o efeito de transformações metalúrgicas na ZAC, ZF e MB sobre as tensões residuais axiais (TR transversal em relação ao cordão de solda) e normais num tubo de aço $9 \mathrm{Cr}$-1Mo que sofre transformações martensiticas durante o resfriamento. No trabalho foram avaliadas diferentes condições para mostrar, entre outros, o efeito isolado das transformações metalúrgicas na ZF sobre a distribuição de TR transversais (que pela simbologia proposta na Seção 2 seria a $\sigma_{x-x}$ ) próximo ao cordão de solda. Como ilustra a Figura 7a, quando o efeito de transformação martensítica foi incluso nos modelamentos (Case A, sem transformação de fase, em relação a Case B), as TR na ZAC e MB reduziram de valores. Como esses autores não simularam as mudanças de limite de escoamento do material, possivelmente essa foi a razão para tensões compressivas na ZF, fato não justificado por eles. Os autores também avaliaram o efeito isolado de limite de escoamento sobre a distribuição de TR longitudinais (que pela simbologia proposta na Seção 2 seria a $\sigma_{y-x}$ ), como ilustra a Figura 7b. Como se observa, a consideração da variação do limite de escoamento (Case A, sem efeito da variação do limite de escoamento, e Case C, com esse efeito) influenciou a distribuição de $\sigma_{y-x}$ apenas na ZF. Conclui-se que a transformação de fase exerce o papel mais importante na distribuição da TR na região adjacente à do cordão de solda.

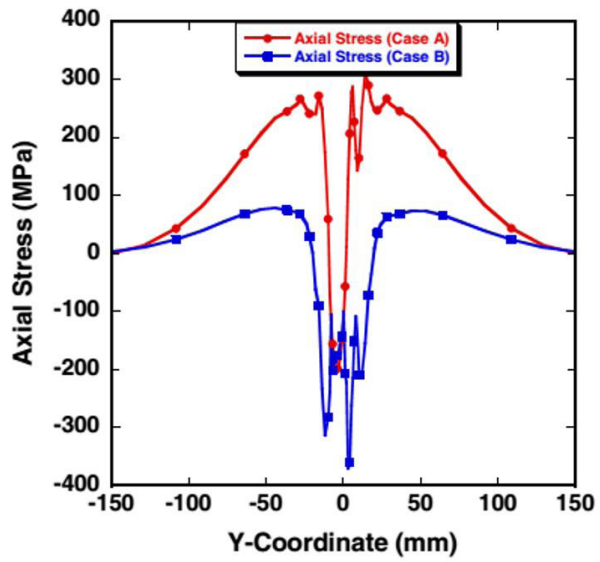

(a)

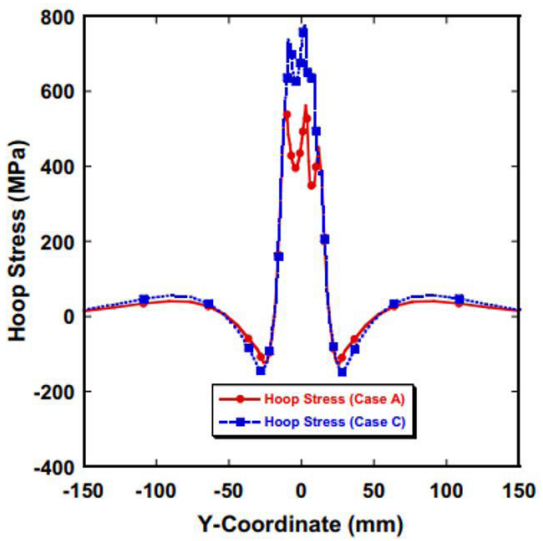

(b)

Figura 7. Distribuição das TR simuladas por Deng e Murakawa (2006) em tubos: (a) TR transversais; (b) TR longitudinais (onde "Case A" não inclui efeito nem de transformação de fase nem o da variação do limite de escoamento, "Case B" inclui efeito da transformação, mas não o da variação do limite de escoamento e "Case C" não inclui efeito da transformação, mas inclui o da variação do limite de escoamento).

Já no trabalho Taljat et al. (1998), em qual os autores soldaram sobre um disco de aço HY-100 e simularam TR axiais, radiais e tangenciais, esses autores não observaram mudanças de TR tal pronunciadas como as que foram relatadas por Deng e Murakawa (2006), ou seja, no trabalho de Taljat et al. (1998) a inclusão de efeito da transformação metalúrgica não alterou o sinal da TR radial. Outro fato interessante que foi observado por Taljat et al. (1998) é que TR trativa no metal de base próximo a ZAC é dobro da TR na própria ZAC. Os autores explicam esta observação pelo fato de que o metal de base não sofre a transformação martensitica, pois não chega à temperatura suficiente para que esta transformação ocorresse. Bezerra et al. (2006) simularam o efeito de mudança da tensão de escoamento (propriedades mecânicas) do material da ZAC sobre as tensões residuais. Os autores observaram que quando o material se transforma em material mais resistente as tensões residuais próximas a cordão de solda aumentam em até 15\%. Por outro lado, Deng e Murakawa (2006) e Taljat et al. (1998) 
afirmam o contrário, que a alteração de tensão de escoamento do material não tem influência sobre as tensões residuais resultantes no cordão de solda.

É importante ressaltar que usar o efeito expansivo das transformações de fase no metal de solda como método proposital de reduzir TR em soldagem já é uma prática estudada, conhecida normalmente pela acrônimo LTT ("Low Temperature Transformation"), ou seja, pela aplicação de consumíveis LTT. Ramjaun et al. (2014) demonstraram que por meio da escolha dos materiais de adição com temperatura de transformação martensitica reduzida (LTT) pode-se conseguir um decréscimo de TR longitudinais num cordão de solda. Ramjaun et al. (2014) ainda estudam o desenvolvimento das TR na soldagem de juntas com múltiplos passes. Foi observado que quando a temperatura entre os passes é tal que os passes anteriores sempre permanecem um pouco acima da temperatura de início da transformação martensitica, as TR diminuem. Isto, segundo os autores, se deve ao fato de que independentemente da quantidade de passes o cordão de solda inteiro sofre a transformação martensitica.

Entretanto, como há uma introdução adicional de energia térmica na peça devido a pré-aquecimento, a contração do metal que não sofreu transformações metalúrgicas será maior. Como consequência, as tensões residuais resultantes também podem aumentar. Por isso numa dada condição de soldagem, especificamente quando material que sofre transformações metalúrgicas é envolvido, seria importante saber o tanto de tensão residual que foi gerado devido a aquecimento e contração natural e devido à transformação metalúrgica. Sabendo esta relação, pode se decidir se é vantajoso utilizar materiais de adição com baixa temperatura de transformação e/ou pré-aquecimento.

Existem outras discordâncias na literatura sobre o papel das transformacos metalúrgicas, que são função da taxa de resfriamento. Enquanto alguns autores, como, por exemplo, Jiang e Yahiaoui (2008), Li et al. (2012) e Sudheesh e Prasad (2011) declaram que uma taxa de resfriamento elevada é benéfica à redução de TR, outros, como, Choi e Mazumder (2002) afirmam o contrário. A situação torna-se mais complicada quando se estuda TR em aços que sofrem transformações metalúrgicas no estado sólido. Geralmente as chapas de aços mais resistentes têm um custo maior e estudos práticos sobre eles são limitados. Uma solução relacionada com custos seria aplicar simulações físicas de ciclos térmicos de soldagem em barras presas, como foi feito por Nitschke-Pagel e Wohlfahrt (2002) e Jones e Alberry, (1978). Entretanto, nos seus trabalhos Nitschke-Pagel e Wohlfahrt (2002) e Jones e Alberry, (1978) se preocuparam mais com resfriamento das barras e a parte de aquecimento foi pouco aprofundada em relação a evolução das TR e transformações metalúrgicas.

\subsection{Influência do pré-aquecimento ou temperatura de interpasse sobre as TR}

A norma americana AWS A3.0-2010 (AWS, 2010) define pré-aquecimento como o calor aplicado à peça para atingir e manter uma dada temperatura previamente ao processo de corte, soldagem ou aspersão térmica. Para o caso da soldagem, é conhecido que o objetivo do pré-aquecimento é reduzir velocidade de resfriamento na zona de região grosseira da ZAC, reduzindo fragilidade e minimizando a susceptibilidade quanto à trinca a frio. Nas Especificações de Procedimento de Soldagem (EPS), pré-aquecimento é considerado como a temperatura mínima que o metal deve estar para se soldar. Nas EPS existem um outro parâmetro de natureza similar, o chamado "temperatura de interpasse", que deve ser a temperatura máxima que o metal deve estar para se soldar. Ou seja, a soldagem (primeiro passe ou entre passes) deve ser realizada com o metal em uma temperatura entre as temperaturas de pré- e interpasse.

Mas, como previsto na Figura 3, pré-aquecimento e a temperatura de interpasse são parâmetros operacionais (variáveis secundárias) que afetam as variáveis primárias da geração de tensões residuais (TR), i.e., volume aquecido e taxa de resfriamento. Quando se faz o pré-aquecimento, um volume adicional da peça será aquecido e sofrerá dilatação-contração, com geração de tensões térmicas (TT) adicionais. Este raciocínio foi desenvolvido por Scotti (2014), onde, por meio de um modelo descritivo, o autor justifica que o pré-aquecimento por si só não reduz a geração de TT e possíveis TR. Lin e Chou (1995) observaram que utilização de temperatura de pré-aquecimento menor (gradiente térmico maior, porém menor volume de metal aquecido) tem impacto positivo na redução das TR. Esta prática também é recomendada pelo Scotti (2014). Assim, como o pré-aquecimento/temperatura de interpasse, além de aumentar o volume de material aquecido, também alteram os ciclos térmicos de soldagem e interferem nas transformações de fase, às vezes torna a sua aplicação contraditória em termos de controle da geração de TR. 
Efeitos metalúrgicos do pré-aquecimento na geração de TR já são mencionados há muito tempo. Por exemplo, de acordo com O'Brien (1997), variando-se os parâmetros de pré-aquecimento, é possível obter taxas de resfriamento mais lentas e microestruturas resultantes mais dúcteis. Ele também sugere que o pré-aquecimento faça com que limite de escoamento seja reduzido em altas temperaturas e deformações plásticas possam ocorrer, aliviando assim TR. Os mesmos efeitos quanto à aplicação de pré-aquecimento foram apresentados por Jones e Alberry (1978).

Já efeitos nocivos do pré-aquecimento ficam evidenciados quando se trata de aços que sofrem transformações metalúrgicas no estado sólido. Lin e Perng (1997) estudaram o efeito de temperatura de pré-aquecimento sobre TR na soldagem de chapas de aço AISI 420. Os autores observaram aumento das TR com aumento da temperatura de pré-aquecimento. Segundo esses autores, o pré-aquecimento faz com que a temperatura de transformação martensitica aumente. Resultados um pouco diferentes foram obtidos por Zubairuddin et al. (2016). Os autores avaliaram experimentalmente e numericamente TR na soldagem de tubos de aço ASTM A335 grau P91 que também, cujo aço também sofre transformação martensítica. Observaram uma redução da TR de pico quando o pré-aquecimento foi aplicado, porém as TR são distribuídas por uma área maior, comparando com as soldas feitas sem pré-aquecimento.

Bezerra et al. (2006) fizeram uma simulação para avaliar a influência do pré-aquecimento sobre as TR, levando-se em consideração o efeito de transformações metalúrgicas quando a energia de soldagem era constante. Os resultados obtidos levam à conclusão de que a transformação metalúrgica na ZAC para um material mais dúctil leva à redução da TR em até $28 \%$, comparado com soldas feitas sem pré-aquecimento. No caso do material se transformar para material mais frágil, a tensão residual aumenta e ficaram localizadas na região de propagação de trincas (ZAC grosseira). Porém, o modelo do Bezerra et al. (2006) não descreva a formação de microconstituintes (ou seja, o efeito expansivo do mesmo), apenas as propriedades finais dos mesmos. Bezerra et al. (2006) ainda observaram que o aumento da temperatura de pré-aquecimento faz com que a TR longitudinal diminuía no centro do cordão, mas aumentando a partir de certa distância do eixo do cordão.

Um exemplo experimental de que pré-aquecimento pode aumentar as TR foi mostrado no trabalho do Lin e Lee (1997), em soldagem TIG em uma chapa de aço AISI 304 (teoricamente sem transformações metalúrgicas de endurecimento). Os autores chegaram à conclusão de que as TR crescem com aumento da temperatura de pré-aquecimento (observaram uma ZAC mais larga com resistência mecânica reduzida). Por outro lado, houve uma redução de TR com aumento da energia de soldagem para peças pré-aquecidas, ao contrário das peças não aquecidos. É interessante apontar que Lin e Lee (1997) fizeram os experimentos em uma chapa de pequena dimensão, o que, provavelmente, faria com que o pré-aquecimento alcançasse todo volume da placa de teste, além de não mencionarem se as placas de teste estavam fixadas ou não. Indicar como o pré-aquecimento é realizado em estudos de seu efeito sobre a geração de TR é de extrema importância, mas nem sempre observado. Como suporte a este comentário, pode-se usar a citação de De e DebRoy (2011), que mencionam que o pré-aquecimento de todo o componente a ser soldado reduz o gradiente de temperatura entre o material de solda e o material circundante, reduzindo assim a deformação térmica (contração) e a tensão residual. Ainda de acordo com estes autores, alternativamente, pontos locais quentes podem ser aplicados em soldagem, respectivamente na frente ou imediatamente atrás da fonte de calor, usando uma fonte externa. Esta abordagem, chamada de tensionamento térmico, reduz também o gradiente de temperatura local, as TT e, consequentemente, a TR. Mas na prática o tensionamento térmico é de difícil aplicação. É importante destacar que De e DebRoy (2011) não discutem que, se por um lado o tensionamento térmico reduz o gradiente térmico, por outro lado aumenta o volume aquecido, que, como já foi apontado, é um dos fatores independentes da geração de TR.

Satoh et al. (1975) observaram que o aumento da temperatura entre os passes causa crescimento de tensões que eles denominaram de tensão de restrição ao final da soldagem (apesar de que diminuía entre cada passe, já que uma temperatura entre passes, igual a de pré-aquecimento, era mantida). Os autores fixaram as placas de teste sob restrição constante pela aplicação de uma pré-carga. A tensão de restrição seria, então, a medição da variação da pré-carga, supostamente proporcional à TR. Schroepfer e Kannengiesser (2014) chegaram à uma conclusão semelhante à de Satoh et al. (1975), usando metodologia similar, mas com equipamentos mais sofisticados. Schroepfer e Kannengiesser (2014) observaram um aumento de tensões (por eles denominadas de tensão de reação) no sentido transversal quando há um aumento da temperatura de interpasse. Schroepfer et al. (2017) verificaram que as tensões de reação crescem se para mais altas temperaturas de pré-aquecimento e de interpasse e maiores calor impostos. 
Lausch et al. (2013) estudaram o efeito da temperatura interpasse e temperatura de pré-aquecimento sobre as forças e momentos desenvolvidos durante a soldagem e depois de resfriamento em chapas de aço EN10028-2 Grau 13CrMoV9-10 de $20 \mathrm{~mm}$ de espessura. As chapas de teste foram unidas pelo processo arco submerso com dois arames e a junta foi preenchida com 19 passes, mantendo a temperatura de interpasse igual a de pré-aquecimento. Os autores mantiveram iguais a temperatura de pré-aquecimento e temperatura interpasse. A energia de soldagem de $25 \mathrm{~kJ} / \mathrm{cm}$ permaneceu constante durante todos os passes. Os autores observaram, Figura 8, que o aumento da temperatura de pré-aquecimento/interpasse de $200^{\circ} \mathrm{C}$ para $240^{\circ} \mathrm{C}$ resultou em acréscimo da força de reação em $50 \%$, sendo que o valor das referidas temperaturas não tem muita influência sobre o momento fletor.
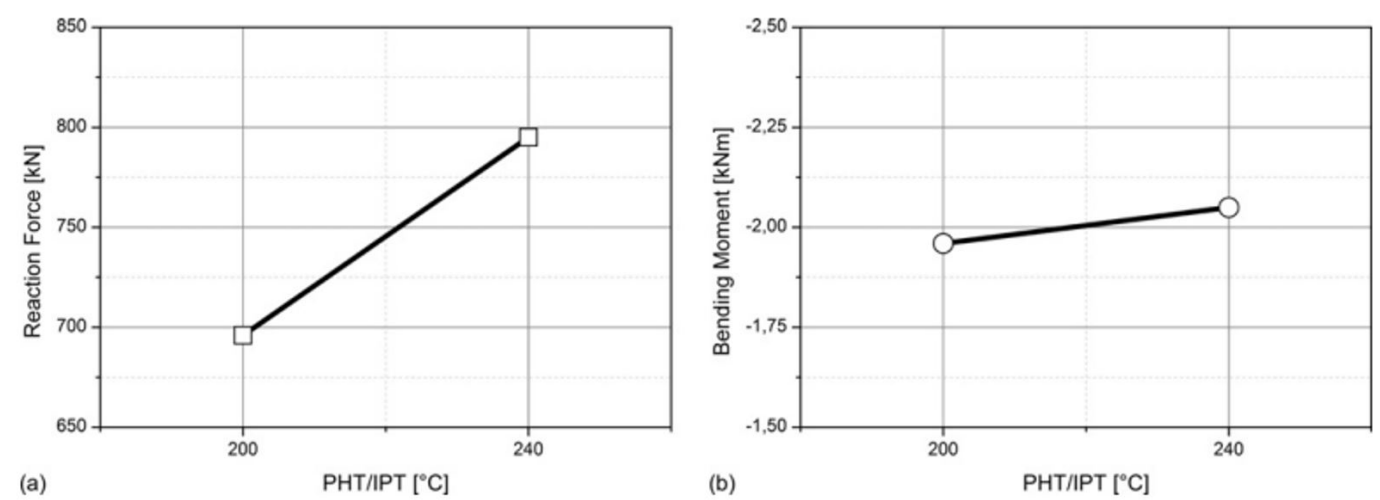

Figura 8. Influência da temperatura de pré-aquecimento (PHT)/temperatura entre os passes (IPT) sobre forças de reação (a) e momento fletor (b) depois de resfriamento até temperatura ambiente, segundo Lausch et al. (2013).

Porém, resultados diferentes foram encontradas na literatura. Lee et al. (2012) estudaram experimentalmente juntas em $\mathrm{T}$ de aços microligados com diferentes preparações de chanfro e compararam uma condição sem pré-aquecimento com uma com pré-aquecimento/temperatura interpasse de $100^{\circ} \mathrm{C}$ e $150{ }^{\circ} \mathrm{C}$, respectivamente. Os autores verificaram aumento ou redução de TR, em função da espessura das chapas que formava a junta. Já Heinze et al. (2012a) compararam simulação e experimentação em juntas de topo, também de aço de alta resistência, com preparação em Heinze et al. (2012a) verificaram uma redução de 60 a $70 \mathrm{MPa}$ nos valores máximos de TR longitudinal e transversal quando a temperatura de interpasse passou $100{ }^{\circ} \mathrm{C}$ a $200{ }^{\circ} \mathrm{C}$. Outro exemplo de efeitos favoráveis de pré-aquecimento sobre as TR foi observado por Teng et al. (2002), os quais avaliaram a influência de TR sobre resistência à fadiga das juntas de topo de aço ASTM A36 sob dois níveis de energia de soldagem $(1,4 \mathrm{~kJ} / \mathrm{mm}$ e $1,2 \mathrm{~kJ} / \mathrm{mm})$. A temperatura de pré-aquecimento foi aumentada gradualmente, de $200^{\circ} \mathrm{Ca} 400^{\circ} \mathrm{C}$. Como resultado, observou-se um decréscimo nas TR longitudinais com aumento da temperatura de pré-aquecimento. Na mesma direção, Lee (2007) avaliou a influência de temperatura de pré-aquecimento e interpasse sobre geração de TR. Verificaram menores TR para temperaturas de pré-aquecimento/interpasse abaixo de $30^{\circ} \mathrm{C}$.

\subsection{Influência das restrições sobre a geração das tensões residuais}

Para os autores deste trabalho, restrição em soldagem pode ser definida como uma limitação ou condição imposta à livre movimentação ou distorção do material quando tensões devido à expansão/contração térmica atuam sobre uma região do material. Em outras palavras, impedem o movimento da chapa durante e depois da soldagem. Dessa forma, o grau de restrição da chapa é definido no presente trabalho como a intensidade das forças de reação às forças devidas às TT. De acordo com Nitschke-Pagel e Wohlfahrt (2002), o grau de restrição, que representa a rigidez de uma construção, é que vai determinar se vai haver distorção ou TR. A restrição em soldagem pode ser de origem interna (autorestrição) ou externa (grampos, suportes, etc.). Um exemplo de autorestrição é a espessura da chapa ou parede de um tubo. 
Em termos de chapas de teste, duas metodologias antagônicas são aplicadas nos trabalhos científicos para se estudar as TR, como será exemplificado a seguir. Na primeira, se solda e se mede as TR na chapa de teste de grandes dimensões (autorestrição interna) ou presa num suporte ou gabarito (restrição externa). Na segunda, a chapa é soldada e aliviada e as TR são medidas sem quaisquer restrições externas. O mesmo se aplica em tubos, que geralmente, devido a autorestrição maior, não se usa suportes ou gabaritos.

Teng e Lin (1998) simularam o efeito de restrição lateral sobre TR transversais em juntas de aço ao carbono e observam aumento de TR quando há restrição da chapa de teste, como mostra a Figura 9. Foi demonstrado por Kohandehghan e Serajzadeh (2011) que o pico das tensões residuais longitudinais pode aumentar em até $7 \%$ quando as chapas de teste foram fixadas. Como justificam os autores, a aplicação de restrição impede a deformação da chapa e a consequente relaxação das tensões residuais. Price et al. (2006) estudaram o efeito de restrições sobre TR longitudinais e transversais na soldagem de chapas de baixo carbono. Para uma energia de soldagem constante, Price et al. observaram aumento de TR transversais e longitudinais no caso da chapa de teste restrita. $O$ aumento máximo de TR transversais para chapa restrita foi observado no centro do cordão de solda, enquanto para chapa livre de restrições a TR transversal no centro do cordão foi compressiva (a mesma TR em chapa restrita se tornou trativa).

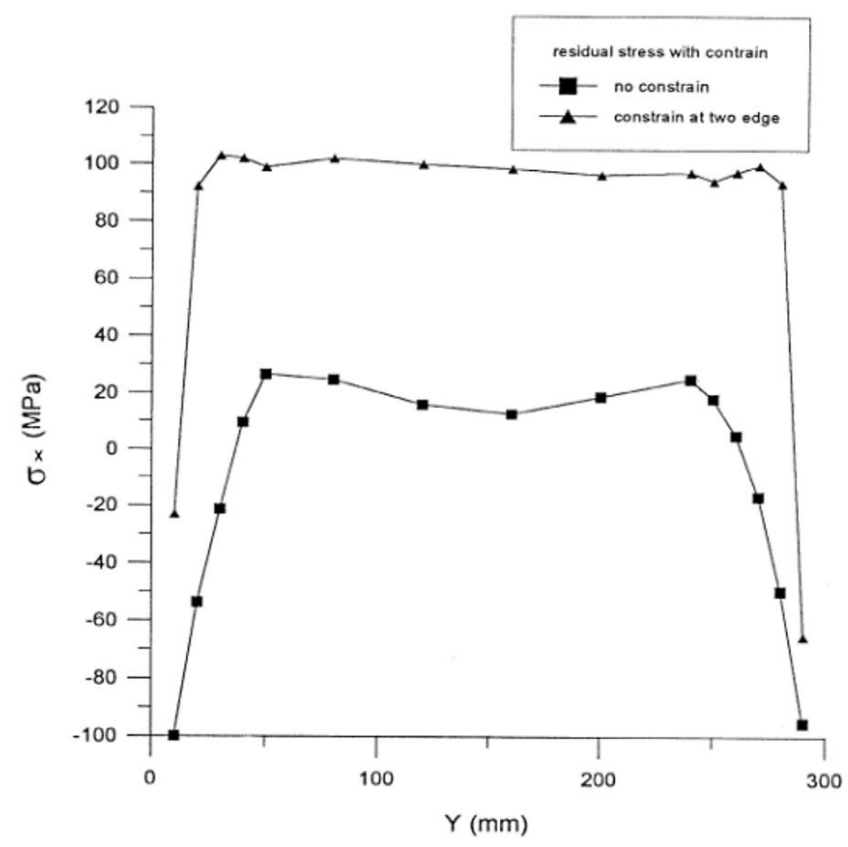

Figura 9. Distribuição de TR transversais em função da restrição da chapa de teste (Teng e Lin, 1998).

A tendência geral é das TR longitudinais e transversais em chapas presas (restrição externa) serem maiores do que as mesmas tensões em chapas livres de restrição. Por exemplo, um dos resultados do trabalho de Lee et al. (2012) sobre TR em juntas de T é que com aumento da espessura a tensão residual transversal aumenta. O motivo para o crescimento da TR com aumento da espessura seria, de acordo com os autores desta revisão, a rigidez maior da chapa mais espessa, o que dificulta a deformação e consequente alivio das tensões residuais. Outro resultado de Lee et al. (2012) seria que as TR decrescem quando um enrijecedor do tipo "mão francesa" é removido após soldagem. Mesma conclusão foi obtida por Teng et al. (2001). Segundo esses autores, quando a espessura da chapa aumenta, os gradientes térmicos tornam-se maiores (uma maior variação de temperatura ao longo da espessura da chapa). Esta explicação ainda deve ser verificada, pois nem sempre maiores gradientes térmicos vão proporcionar maiores TR, como foi mostrado na seção que se tratou da influência do volume aquecido sobre a geração de TT. 
Teng et al. (2001) procuram justificar o alivio de TR transversais após a retirada de restrições pela deformação angular, que induz tensões de compressão na região da ZAC e, assim, segundo os autores, ocorre alivio das TR. Por sua vez, Park et al. (2012), estudando o efeito de pré-tensionamento de uma junta em T sobre as tensões residuais e distorções, observaram que quanto maior a espessura da chapa o efeito de pré-tensionamento sobre distorções angulares é menor. Os autores chegam à conclusão de que o pré-tensionamento diminui mais as distorções quando chapas finas são avaliadas.

No trabalho de Teng et al. (2001), os autores demonstraram que quando as restrições são retiradas ocorre alivio das tensões residuais. Entretanto, as chapas soldadas sofreram distorção. É de ressaltar que, de acordo com Nitschke-Pagel e Wohlfahrt (2002), pode-se dizer que a relaxação das TR resulta em menos de $1 \%$ em deformação plástica. Estefen et al. (2012) estudam o comportamento das TR numa junta de topo feita por soldagem MIG semiautomática e soldagem MIG Duplo Arame. Esses autores removeram a restrição da chapa no dia seguinte a operação de soldagem e acompanharam evolução de TR em função do tempo. Foi observado a relaxação continua das TR durante 14 dias de observação. Diferentemente do Teng et al. (2001), o Estefen et al. não avaliaram a distorção da chapa durante o período de observação e nenhum dos dois trabalhos apresenta a variação temporal de TR na chapa restrita. Além disso, Park et al. (2012) observaram que o maior decréscimo das distorções angulares ocorre quando a pré-tensionamento é retirado $60 \mathrm{~min}$ depois da soldagem.

Sang-Hyong et al. (2006) demonstraram que a magnitude de TR é proporcional à razão entre largura e comprimento da chapa de teste. No caso, a largura da chapa é o seu comprimento soldado e o comprimento da chapa de teste seria o dobro da distância entre eixo longitudinal do cordão (Y) e a borda lateral da chapa de teste/fixador da chapa. Nitschke-Pagel e Wohlfahrt (2002), por outro lado, consideram que o grau de restrição não necessariamente é equivalente ao tamanho da peça (maior peça tem maior grau de restrição). Diferentemente das afirmações de Lee et al. (2012) e Teng et al. (2001), que observaram aumento de TR com aumento da espessura da chapa, Nitschke-Pagel e Wohlfahrt atribuem essa tendência à razão entre área aquecida e área fria. Nitschke-Pagel e Wohlfahrt (2002) afirmam que para uma chapa muito fina, mas soldada com laser ou feixe de elétrons, o grau de restrição pode ser maior (menor relação entre o volume quente e volume frio) do que para uma chapa grossa, mas soldada com arco submerso. Os autores do presente trabalho ressaltam que a afirmação de Nitschke-Pagel e Wohlfahrt (2002) deveria estar condicionada às dimensões e resistência mecânica da chapa (se aplicaria em chapas maiores e de maiores resistências).

Outro fator importante seria o tipo de restrição da chapa de teste. Como apontam Kohandehghan e Serajzadeh (2011), o uso de diferentes modos de restrição da peça altera o ciclo térmico da solda e, por consequência, as tensões residuais. Em outro trabalho, Fu et al. (2014) investigaram a influência de tipo de restrição sobre TR e distorções na soldagem a arco de chapas em junta de T. Diferente do trabalho do Kohandehghan e Serajzadeh (2011), Fu et al. (2014) não observaram influência significativa do tipo de restrição sobre as tensões residuais longitudinais e as tensões transversais aumentam com a aplicação de restrição. Akbari Mousavi e Miresmaeili (2008) estudaram a influência do tipo de restrição sobre as tensões residuais e deformações na soldagem TIG das chapas de aço AISI 304. De forma similar à Fu et al. (2014), os autores apontam que aplicação de restrição no sentido perpendicular à superfície da chapa diminui as distorções, porém aumenta as tensões residuais transversais quase ao triplo, comparado com a chapa livre. Outros resultados similares aos de Fu et al. (2014) foram obtidos por Heinze et al. (2012b), onde os autores estudaram o desenvolvimento das TR sob várias condições de restrição das juntas de topo. Foi observado que quanto maior a restrição à contração transversal, maiores são TR transversais enquanto as TR longitudinais não foram afetadas significativamente. Em relação às TR longitudinais, pouca influência foi observada.

Tensionamento mecânico durante soldagem tem sido usado para simular restrições e usado em trabalhos já mencionados, como os de Satoh et al. (1975) e Schroepfer e Kannengiesser (2014). Schroepfer et al. (2015, 2017) descrevem dispositivos em que pré-cargas de diferentes valores são aplicadas na direção transversal ao cordão de solda e quanto maior a carga, maior a restrição. Por esses autores, no sentido transversal existem as chamadas por eles de "tensões locais de soldagem", devidas às contrações volumétricas e taxa de resfriamento/transformação de fase (como proposto na Figura 3) e as "Tensões de Reação Global", devido às forças de reações dos fixadores e suportes. A sobreposição destas forças é o que faria com que as tensões sob restrição sejam maiores, como já mencionado nesta revisão. Schroepfer et al. (2017) observaram que, de uma forma geral, o nível de TR transversal era menor na ZAC em comparação com a do metal de solda. No entanto, em componentes soldados, pode ocorrer 
uma superposição da reação global e aumentar o aumento dos momentos de flexão se a distorção lateral e angular da solda for restringida.

Schroepfer et al. $(2015,2017)$ também apresentam o conceito de intensidade de restrição $\left(R_{\mathrm{fy}}\right)$, estabelecido por Satoh et al. (1975), para a quantificação e comparação de condições de restrição de diferentes juntas de topo. De forma simplificada (sem levar em conta o efeito Poisson e que todos os esforço é estático), os referidos autores apresentam a Equação 1 (onde $\Delta y$ é a variação da largura da chapa, a partir do cordão de solda até o ponto de fixação da mesma, pela aplicação da forca Fy externa - pré-carga), para dizer que a intensidade de restrição na direção transversal $\left(\mathrm{R}_{\mathrm{Fy}}\right)$ é a rigidez do componente em relação ao cordão de solda com base no comprimento do cordão $L_{w}$. Quer dizer, quanto mais longo o cordão e mais estreita a chapa, maior $R_{F y}$. Indiretamente, a espessura está chapa está atendida pela Equação 1, uma vez que $\Delta y$ depende da espessura para um dada forca externa.

$$
R_{F y}=F y /(L w \cdot \Delta y)
$$

Schroepfer et al. (2017) sugerem, a partir de experimentos baseados em tensionamento mecânico, que uma menor contração (menor volume aquecido) diminui as tensões de reações. Além disso, uma temperatura de interpasse reduzida leva a tensões de reação mais baixas. O efeito do calor imposto é relativamente pequeno e não estatisticamente significativo na estreita faixa de parâmetros analisados. Também justificam os altos esforços nas soldagens dos passes de raiz, frente à pequena seção para suportar a carga devido às TT (passe de raiz é mais susceptível a tricas).

\section{Discussão Geral}

Encontra-se na literatura diversos trabalhos sobre tensões residuais, sejam obtidos por meio experimental, sejam por simulação numérica. Entretanto, não se consegue através deles se definir e muito menos quantificar, ou pelo menos qualificar, o efeito separado de cada fator sobre a tensão residual como um todo.

Inicia-se com a dificuldade em se diferenciar forças de origem térmicas de tensores térmicas e tensões térmicas de tensões residuais. Alguns trabalhos argumentam, por exemplo, que houve deformações ou mesmo colapso devido às tensões residuais. Withers (2007) afirma que as TR são a principal causa da falha de equipamentos e estruturas metálicas em serviço. Como citam Joseph et al. (2005), as TR são a principal causa das falhas na ZAC das juntas dissimilares de aço ferritico e austenitico. No presente trabalho, procurou-se fazer esta diferença, propondo que tensões térmicas sejam as tensões geradas durante o aquecimento e resfriamento localizados por soldagem (na verdade, são geradas forças térmicas, de natureza vetorial, mas que por agirem sobre uma área finita, se apresentam como tensão, de caráter escalar). Ao término do resfriamento, as tensões térmicas criadas e que não se aliviaram, seja por levar à deformação (com mudança ou não de forma), seja por levar a uma fratura, ficam acumuladas, aí sim podendo receber a denominação de tensão residual (apesar de mesma intensidade e sentido das tensões térmicas finais). A tensão residual pode também, aliada a outros esforços externos, levar à deformação ou colapso, mas são coisas diferentes.

Uma segunda dificuldade se origina da homogeneização da nomenclatura aplicada. Alguns autores consideram que o eixo $X$ num plano $X-Y$ sobre a chapa se refira ao eixo longitudinal da solda, enquanto o eixo $Y$ se refira ao eixo transversal, muitas vezes sem orientar o leitor, como por exemplo em Pouget e Reynolds (2008), Teng e Lin (1998) e Park et al. (2004), onde os autores utilizaram diferentes sistemas de referência e nomenclaturas diferentes para medir as TR em chapas planas. O presente trabalho procurou seguir a tendência mais comum, de se ter o eixo $Y$ referindo-se ao eixo longitudinal da solda. Sendo assim, neste trabalho se propôs denominar de $\sigma_{y}$ a tensão térmica (ou residual) gerada na direção Y, que é o eixo longitudinal do cordão de solda.

Mas este não é o maior problema ao se usar a literatura técnica disponível sobre tensores residuais. Levando-se em consideração a natureza escalar das tensões mecânicas e o caráter não isotrópico das propriedades mecânicas do material, muitas vezes não fica claro para o leitor a direção que esta tensão está agindo, seja na direção do eixo X ou $Y$, ou seja, se faz apenas referência à $\sigma_{x}$ e $\sigma_{y}$. No presente trabalho procurou-se adotar uma nomenclatura mais simples, com o uso de dois índices de referência para os eixos, a saber, $\sigma_{A B}$, onde $A$ é o eixo da direção que a tensão que se quer referir está agindo e B o eixo ao longo do qual a tensão está agindo (A e B podem 
ser $X$ ou $Y$, em qualquer combinação). Por exemplo, $\sigma_{y-x}$ seria, então, a tensão longitudinal ( $\left.\sigma_{y}\right)$ ao longo do eixo $X$, à uma distância do eixo de referência $Y$ a ser definida pelo autor do texto. Naturalmente, ao longo da espessura do material, haverá infinitos planos $X-Y$, o que demanda também do autor fazer referência à profundidade em que está o plano X-Y das referidas tensões. Finalmente, se negligenciada, a tensão normal (direção da espessura) deve se sempre mencionada.

Além das questões de não homogeneidade de definições e terminologia, a literatura muitas vezes reflete uma visão subjetiva dos autores do presente trabalho, baseada em percepções e experiências próprias, ou seja, a de que os fatores que governam a geração de tensões térmicas são interligados e provavelmente sempre não ortogonais (não se consegue alterar um sem modificar outros). Por exemplo, ao se aumentar a velocidade de resfriamento da solda, por um lado haverá provavelmente um menor volume de material aquecido e resfriado (menor volume contraído, menor força térmica de tração), mas por outro lado maior velocidade de resfriamento pode gerar microconstituintes que se expandem ao se transformarem (minimizando tensões trativas pelas tensões compressivas criadas) ou que sejam muitos duros (não absorvem a tensões térmicas geradas por deformação plástica). Adicionalmente, muitas vezes um fator não governa a geração das tensores térmicas diretamente, mas indiretamente, como no caso da energia de soldagem. Como se vê na Figura 3, o aumento da energia de soldagem afeta dois fatores governantes e concorrentes da geração de tensões térmicas, ou seja, o volume de material aquecido e a transformações metalúrgicas devido à taxa de resfriamento.

Não se vê com muita facilidade autores tentando em seus estudos isolar os efeitos que agem sobre a geração de tensores térmicas. Até por que, além da dificuldade de se isolar os fatores, existe a dificuldade de identificar estes fatores com maior clareza. Esta é com certeza a razão para tanta discrepância dos resultados verificados e apresentados no presente trabalho.

\section{Conclusão}

Caso seja tentado tirar conclusões da literatura, por esta revisão elas seriam:

a) O aumento da energia de soldagem mostrou gerar mais tensões residuais de acordo com Lin e Chou (1995), Lin e Lee (1997), Unnikrishnan et al. (2014), Scotti (2014), Schroepfer e Kannengiesser (2014) e Schroepfer et al. (2017), mas há resultados discordantes, de acordo com Colegrove et al. (2009), Xu et al. (2014) (seção 3.1);

b)O aumento do volume de material aquecido (ZF+ZAC+MB) é um dos fatores determinantes na geração da tensão residual, de acordo com Masubuchi (1980), Teng et al. (2002), Vakili-Tahami e Sorkhabi (2009), mas negligenciado por Lin e Lee (1997), Colegrove et al. (2009), Xu et al. (2014), ao se estudar, por exemplo, o efeito da energia de soldagem ou transformação de fases (seção 3.1.1);

c) O aumento da espessura da chapa mostrou gerar mais tensões residuais de acordo com Teng et al. (2002), Vakili-Tahami e Sorkhabi (2009), mas há resultados discordantes de acordo com Lee et al. (2012) (seção 3.1.1);

d)A aplicação de resfriamento forçado mostrou aliviar as tensões residuais no metal de base, como afirmam Sudheesh e Prasad (2011). Por outro lado, os mesmos autores comentam sobre efeito desprezível do resfriamento sobre as TR na ZF e ZAC (seção 3.2). Os resultados diferentes sobre a influência do resfriamento forçado foram obtidos por Jiang et al. (2012). Os autores observaram redução de pico de TR longitudinais na ZAC e ZF e aumento nas regiões mais afastadas do cordão de solda quando o resfriamento forçado foi aplicado; (seção 3.1.1).

e) O aumento da taxa de resfriamento de formação de martensita mostrou gerar menos tensões residuais de acordo com Kumar et al. (2017), mas há resultados discordantes de acordo com Jones e Alberry (1978) (seção 3.1.2);

f) A aplicação de pré-aquecimento mostrou gerar mais tensões residuais de acordo com Lin e Lee (1997), Satoh et al. (1975), Schroepfer e Kannengiesser (2014) e Schroepfer et al. (2017), mas há resultados discordantes, de acordo com Heinze et al. (2012a), Lee et al. (2012) e Lee (2007) (seção 3.2); 
g) A aplicação de restrição externa mostrou mais tensões residuais e maior intensidade de acordo com Kohandehghan e Serajzadeh (2011) e Teng e Lin (1998), mas há resultados discordantes de acordo com Fu et al. (2014), Heinze et al. (2012b) e Akbari Mousavi e Miresmaeili (2008) (seção 3.3).

\section{Agradecimentos}

Os autores gostariam de agradecer ao programa de Pós-graduação em Engenharia Mecânica da UFU pela oportunidade para realização do trabalho. Também ao CNPq pela bolsa do projeto 149308/2014-0, FAPEMIG e CAPES, pelo fornecimento de bolsa de pesquisa e de bolsas de estudo (doutorado).

\section{Referências}

Akbari Mousavi SAA, Miresmaeili R. Experimental and numerical analysis of residual stress distributions in TIG welding process for 304L stainless steel. Journal of Materials Processing Technology. 2008;208(1-3):383-394. http://dx.doi.org/10.1016/j. jmatprotec.2008.01.015.

American Welding Society. AWS A3.0M/A3.0:2010: standard welding terms and definition. 12th ed. Miami: AWS; 2010. 162 p.

Bezerra AC, Scotti A, Rade DA. Effect of the preheating on welding residual stresses. Soldagem e Inspeção. 2006;11(1):54-61. [em português]

Chang P-H, Teng T-L. Numerical and experimental investigations on the residual stresses of the butt-welded joints. Computational Materials Science. 2004;29(4):511-522. http://dx.doi.org/10.1016/j. commatsci.2003.12.005.

Choi J, Mazumder J. Numerical and experimental analysis for solidification and residual stress in the GMAW process for AISI 304 stainless steel. Journal of Materials Science. 2002;37(10):2143-2158. http://dx.doi.org/10.1023/A:1015258322780.

Colegrove P, Ikeagu C, Thistlethwaite A, Williams S, Nagy T, Suder $W$, et al. Welding process impact on residual stressand distortion. Science and Technology of Welding and Joining. 2009;14(8):717725. http://dx.doi.org/10.1179/136217109X406938.

De A, DebRoy T. A perspective on residual stresses in welding. Science and Technology of Welding and Joining. 2011;16(3):204-208. http://dx.doi.org/10.1179/136217111X12978476537783.

Deng D, Murakawa H. Prediction of welding residual stress in multipass butt-welded modified $9 \mathrm{Cr}-1$ Mo steel pipe considering phase transformation effects. Computational Materials Science. 2006;37(3):209-219. http://dx.doi.org/10.1016/j. commatsci.2005.06.010.

Deng D. FEM prediction of welding residual stress and distortion in carbon steel considering phase transformation effects. Materials \& Design. 2009;30(2):359-366. http://dx.doi.org/10.1016/j. matdes.2008.04.052.

Eisazadeh $\mathrm{H}$, Aidun DK. Investigation of transient/residual strain and stress in dissimilar weld. Journal of Manufacturing Processes. 2017;26:372-381. http://dx.doi.org/10.1016/j.jmapro.2017.03.003.

Estefen SF, Gurova T, Werneck D, Leontiev A. Welding stress relaxation effect in butt-jointed steel plates. Marine Structures. 2012;29(1):211225. http://dx.doi.org/10.1016/j.marstruc.2012.06.002.

Fu G, Lourenco MI, Duan M, Estefen SF. Effect of boundary conditions on residual stress and distortion in T-joint welds. Journal of Constructional Steel Research. 2014;102:121-135. http://dx.doi. org/10.1016/j.jcsr.2014.07.008.

Heinze C, Schwenk C, Rethmeier M. Numerical calculation of residual stress development of multi-pass gas metal arc welding. Journal of Constructional Steel Research. 2012a;72:12-19. http://dx.doi. org/10.1016/j.jcsr.2011.08.011.
Heinze C, Schwenk C, Rethmeier M. Numerical calculation of residual stress development of multi-pass gas metal arc welding under high restraint conditions. Materials \& Design. 2012b;35:201-209. http://dx.doi.org/10.1016/j.matdes.2011.09.021.

Ishizaki Y, Asai S, Tanabe T, Yasuda Y, Takebayashi H. Development of GTAW System using CO2 Cooling for reducing residual stress. Materials Science and Engineering: A. 2008;480:411-418.

Jiang W, Yahiaoui $\mathrm{K}$. Influence of cooling rate on predicted weld residual stress build-up in a thick walled piping intersection. In: American Society of Mechanical Engineers. ASME 2008 Pressure Vessels and Piping Conference, Volume 6: Materials and Fabrication, Parts A and B; 2008 July 27-31; Chicago, Illinois. New York: ASME; 2008. p. 267-277. http://dx.doi.org/10.1115/ PVP2008-61101

Jiang $W$, Zhang $Y$, Woo W. Using heat sink technology to decrease residual stress in 316 L stainless steel welding joint: finite element simulation. International Journal of Pressure Vessels and Piping. 2012;92:56-62. http://dx.doi.org/10.1016/j.ijpvp.2012.01.002.

Jones WKC, Alberry PJ. The role of phase transformations in the development of residual stresses during the welding of some fast reactor steels. In: British Nuclear Energy Society at the Institution of Civil Engineers. Proceedings of the International Conference on Ferritic steels for fast reactor steam generators. London: BNES; 1978. p. 471-475. http://dx.doi.org/10.1680/ fsffrsgv2.00490.0037.

Joseph A, Rai SK, Jayakumar T, Murugan N. Evaluation of residual stresses in dissimilar weld joints. International Journal of Pressure Vessels and Piping. 2005;82(9):700-705. http://dx.doi. org/10.1016/j.ijpvp.2005.03.006.

Kim YS, Eagar TW. Metal transfer in pulsed current gas metal arc welding. Welding Research Suplement. 1993;72(7):279-287.

Kohandehghan AR, Serajzadeh S. Arc welding induced residual stress in butt-joints of thin plates under constraints. Journal of Manufacturing Processes. 2011;13(2):96-103. http://dx.doi. org/10.1016/j.jmapro.2011.01.002.

Kumar R, Ghosh PK, Kumar S. Thermal and metallurgical characteristics of surface modification of AISI 8620 steel produced by TIG arcing process. Journal of Materials Processing Technology. 2017;240:420431. http://dx.doi.org/10.1016/j.jmatprotec.2016.10.020.

Lancaster J. Engineering catastrophes causes and effects of major acidentes. 3rd ed. Cambridge: Woodhead Publishing Limited; 2005. 289 p. http://dx.doi.org/10.1201/9781439832745.

Lausch T, Kannengiesser T, Schmitz-Niederau M. Multi-axial load analysis of thick-walled component welds made of 13CrMoV9-10. Journal of Materials Processing Technology. 2013;213(7):12341240. http://dx.doi.org/10.1016/j.jmatprotec.2013.01.008.

Lee $\mathrm{C}-\mathrm{H}$, Chang $\mathrm{KH}$. Prediction of residual stresses in high strength carbon steel pipe weld considering solid-state phase transformation 
effects. Computers \& Structures. 2011;89(1-2):256-265. http:// dx.doi.org/10.1016/j.compstruc.2010.10.005.

Lee $\mathrm{C}-\mathrm{H}$. Computational modelling of the residual stress evolution due to solid-state phase transformation during welding. Modelling and Simulation in Materials Science and Engineering. 2008;16(7):116. http://dx.doi.org/10.1088/0965-0393/16/7/075003.

Lee CK, Chiew SP, Jiang J. Residual stress study of welded high strength steel thin-walled plate-to-plate joints. Part 1: experimental study. Thin-walled Structures. 2012;56:103-112. http://dx.doi. org/10.1016/j.tws.2012.03.015.

Lee HW. Weld metal hydrogen-assisted cracking in thick steel plate weldments. Materials Science and Engineering A. 2007;445446:328-335. http://dx.doi.org/10.1016/j.msea.2006.09.046.

Li Y, Kaji Y, Igarashi T. Effects of thermal load and cooling condition on weld residual stress in a core shroud with numerical simulation. Nuclear Engineering and Design. 2012;242:100-107. http:// dx.doi.org/10.1016/j.nucengdes.2011.10.040.

Lin YC, Chou CP. A new technique for reducing the residual stress induced by welding in type 304 stainless steel. Journal of Materials Processing Technology. 1995;48(1-4):693-698. http:// dx.doi.org/10.1016/0924-0136(94)01710-I.

Lin YC, Lee KH. Effect of preheating on the residual stress in type 304 stainless steel weldment. Journal of Materials Processing Technology. 1997;63(1-3):797-801. http://dx.doi.org/10.1016/ S0924-0136(96)02727-6.

Lin YC, Perng JY. Effect of welding parameters on residual stress in type 420 martensitic stainless steel. Science and Technology of Welding and Joining. 1997;2(3):129-132. http://dx.doi. org/10.1179/stw.1997.2.3.129.

Masubuchi K. Analysis of welded structures: residual stresses, distortion and their consequences. New York: Pergamon Press; $1980.641 \mathrm{p}$.

Michaelis. Dicionário Michaelis da Língua Portuguesa. Rio de Janeiro: Melhoramentos; 2016.

Naka T. Shrinkage and cracking in welds. Tokyo: Komine Publishing Co.; 1950

Nitschke-Pagel T, Wohlfahrt H. Residual stress in welded joint-sources and consequences. Materials Science Forum. 2002;404-407: 215-226. http://dx.doi.org/10.4028/www.scientific.net/ MSF.404-407.215

O'Brien RL. Jefferson's welding encyclopedia. 8th ed. Miami: American Welding Society; 1997. 758 p.

Palani PK, Murugan N. Selection of parameters of pulsed current gas metal arc welding. Journal of Materials Processing Technology. 2006;172(1):1-10. http://dx.doi.org/10.1016/j. jmatprotec.2005.07.013.

Pamnani R, Vasudevan M, Jayakumar V, Vasantharaja P, Ganesh KC. Numerical simulation and experimental validation of arc welding of DMR-249A steel. Defence Technology. 2016;12(4):305-315. http://dx.doi.org/10.1016/j.dt.2016.01.012.

Park J-U, An G, Lee H-W. Effect of external load on angular distortion in fillet welding. Materials \& Design. 2012;45:403-410. http:// dx.doi.org/10.1016/j.matdes.2012.06.006.

Park MJ, Yang HN, Jang DY, Kim JS, Jin TE. Residual stress measurement on welded specimen by neutron diffraction. Journal of Materials Processing Technology. 2004;155-156:1171-1177. http://dx.doi. org/10.1016/j.jmatprotec.2004.04.393.

Pouget $\mathrm{G}$, Reynolds AP. Residual stress and microstructure effects on fatigue crack growth in AA2050 friction stir welds. International Journal of Fatigue. 2008;30(3):463-472. http://dx.doi.org/10.1016/j. ijfatigue.2007.04.016.
Price JWH, Paradowska A, Joshi S, Finlayson T. Residual stress measurement by neutron diffraction and theoretical estimation in single weld bead. International Journal of Pressure Vessels and Piping. 2006;83(5):381-387. http://dx.doi.org/10.1016/j. ijpvp.2006.02.015.

Ramjaun T, Stone HJ, Karlsson L, Kelleher J, Moat RJ, Kornmeier $J R$, et al. Effect of interpass temperature on residual stresses in multipass welds produced using low transformation temperature filler alloy. Science and Technology of Welding and Joining. 2014;19(1):44-51. http://dx.doi.org/10.1179/136 $2171813 Y .0000000162$.

Sang-Hyong L, Kyong-Ho C, Gab-Chul J. Effect of the degree of restraint against thermal expansion and contraction on welding residual stress, Int. Journal of Modern Physics. 2006;20(25):4075-4080. http://dx.doi.org/10.1142/S021797920604088X.

Satoh, K., Terai, K., Ohkuma, S.Y., Kinoshita, T. Theoretical study on transient restraint stress in multi-pass welding. Transactions of the Japan Welding Society. 1975;6(1):42-52

Schroepfer D, Kannengiesser T. Correlating welding reaction stresses and weld process conditions for high-strength steel S960QL. Welding in the World. 2014;58(3):423-432. http://dx.doi. org/10.1007/s40194-014-0127-x.

Schroepfer D, Kromm A, Kannengiesser T. Improving welding stresses by filler metal and heat control selection in component-related butt joints of high-strength steel. Welding in the World. 2015;59(3):455-464. http://dx.doi.org/10.1007/s40194-014-0219-7.

Schroepfer D, Kromm A, Kannengiesser T. Engineering approach to assess residual stresses in welded components. Welding in the World. 2017;61(1):91-106. http://dx.doi.org/10.1007/ s40194-016-0394-9.

Scotti, A. Five bars and one bar models for thermal stress generation in the FZ, HAZ and BM during arc welding. Soldagem e Inspeção. 2014;19(1):82-90. http://dx.doi.org/10.1590/S010492242014000100010.

Sudheesh, RS, Prasad, NS. Finite element study of residual stresses and distortions in arc welding with a trailing liquid nitrogen heat sink. International Journal of Numerical Methods for Heat \& Fluid Flow. 2011;21(8):1050-1065.

Taljat B, Radhakrishnan B, Zacharia T. Numerical analysis of GTA welding process with emphasis on post-solidification phase transformation effects on residual stresses. Materials Science and Engineering A. 1998;246(1-2):45-54. http://dx.doi.org/10.1016/ S0921-5093(97)00729-6.

Teng T, Fung C-P, Chang P-H. Effect of weld geometry and residual stresses on fatigue in butt-welded joints. International Journal of Pressure Vessels and Piping. 2002;79(7):467-482. http:// dx.doi.org/10.1016/S0308-0161(02)00060-1.

Teng T-L, Fung C-P, Chang P-H, Yang W-C. Analysis of Residual Stresses and Distortions in T-joints Fillet Welds. International Journal of Pressure Vessels and Piping. 2001;78(8):523-538. http://dx.doi. org/10.1016/S0308-0161(01)00074-6.

Teng T-L, Lin C-C. Effect of welding conditions on residual stress due to butt welds. International Journal of Pressure Vessels and Piping. 1998;75(12):857-864. http://dx.doi.org/10.1016/ S0308-0161(98)00084-2.

Unnikrishnan R, Idury KSNS, Ismail TP, Bhadauria A, Shekhawat SK, Khatirkar RK, et al. Effect of heat input on the microstructure, residual stresses and corrosion resistance of $304 \mathrm{~L}$ austenitic stainless steel weldments. Materials Characterization. 2014;93:1023. http://dx.doi.org/10.1016/j.matchar.2014.03.013.

Vakili-Tahami F, Sorkhabi AHD. Finite element analysis of thickness effect on the residual stress in butt-weld 2.25Cr1Mo steel 
plates. Journal of Applied Sciences. 2009;9(7):1331-1337. http:// dx.doi.org/10.3923/jas.2009.1331.1337.

Withers PJ. Residual stress and its role in failure. Reports on Progress in Physics. 2007;70(12):2211-2264. http://dx.doi.org/10.1088/00344885/70/12/R04.

Xu M, Chen J, Jin Y, Li Y, Lu H. Effects of weld metal strength and and transformation temperature on welding residual stress. Science and Technology of Welding and Joining. 2015;20(3):208-215. http://dx.doi.org/10.1179/1362171814Y.0000000274.

Xu S, Wei R, Wang W, Chen X. Residual stresses in the welding joint of the nozzle-to-head area of a layered high-pressure hydrogen storage tank. International Journal of Hydrogen
Energy. 2014;39(21):11061-11070. http://dx.doi.org/10.1016/j. ijhydene.2014.05.066.

Ye Y, Cai J, Jiang X, Dai D, Deng D. Influence of groove type on welding-induced residual stress, deformation and width of sensitization region in a SUS304 steel butt welded joint. Advances in Engineering Software. 2015;86:39-48. http:// dx.doi.org/10.1016/j.advengsoft.2015.04.001.

Zubairuddin M, Albert SK, Vasudevan M, Mahadevan S, Chaudhri V, Suri VK. Thermomechanical analysis of preheat effect on grade P91 steel during GTA welding. Materials and Manufacturing Processes. 2016;31(3):366-371. http://dx.doi.org/10.1080/10 426914.2015.1025964. 